\title{
EDITOR'S ACKNOWLEDGMENTS
}

Many people helped in the creation of this book, both directly and indirectly. First, I would like to thank Alexandra Zirkle with whom I first shared the idea one early morning in Los Angeles in our apartment in Koreatown. Her enthusiastic response encouraged me to contact others. Sholeh Quinn welcomed the idea right away and signed on to write an essay. Her positive reception was a great encouragement at the onset of a journey that has taken five winters to finish. I am thankful to my University of Chicago teachers, John E. Woods, Cornell Fleischer, Frank D. Lewis, and Fred Donner; and to my other teachers such as Iraj Afshar, Manuchehr Sotodeh, 'Abdul Hussein Nava'i, Muhammad Bastani-Parizi, and Mohammad Reza Shafiei Kadkani, whom I only got to know through their works. Special thanks go to my colleagues and friends at Chicago, Nicolay Antov, Abdurrahman Atçıl, and Zahit Atçl who supported the idea and helped me gather much needed momentum at the beginning of the project. Rudi Matthee has been an unwavering support and a great friend. I am grateful to Anne Routon, former Columbia University Press editor, who welcomed the proposal; her successor, Caelyn Cobb; and Miriam Grossman for making the process easy and enjoyable.

I would like to thank the anonymous reviewers for their helpful comments and ideas for improving the book. My sincere gratitude goes to each one of my contributing authors: Sheila Blair, Rudi Matthee, Nikolay Antov, Corinne Lefèvre, Maryam Moazzen, Abdurrahman Atçıl, Audrey Truschke, Ata Anzali, Betul Yavuz, Arthur Buehler, Hüseyin Yılmaz, Azfar Moin, Sholeh Quinn, Zahit Atçıl, 
Jane Mikkelson, Taymiya R. Zaman, Sajjad Rizvi, Ahab Bdaiwi, Asad Q. Ahmad, Matthew Melvin-Koushki, Tuna Artun, Eva Orthmann, Paul Losensky, Berat Açıl, Murat Umut Inan, Rajeev Kinra, Esra Akın-Kıvanç, Keelan Overton, and Jake Benson. Without their love of historical insight and exceptional expertise in their fields, this book would not have come into being.

I am thankful to many of my students at the University of Southern California who helped me identify key challenges in teaching the history of the early modern empires, conceive of methods and pedagogical resources to address the difficulties, and offered me their unalloyed feedback during many classroom discussions while the manuscript was in preparation. In many ways, the content and structure of this book is a result of those discussions. Very special thanks go to my two student assistants, Ida Abhari and Sama Shah, in the Department of Middle East Studies for their invaluable editorial assistance. I am thankful to Martin Hinz who meticulously designed the map, and to Philip Grant who generously accepted to offer his time and expertise to tackle the volume's complex index.

I would like to express my gratitude to Azad Amin Sadr, Emran El-Badawi, Metin Yuksel, and Kaveh Hemmat for their precious friendship all these years; to khaleh Ameneh, Soheyl, and Sara. I am forever grateful to my wife Alexandra Zirkle for her love, scholarship, and all the ways we have nurtured and strengthened our bonds; and to our son Soroush for being an unremitting source of delight and surprise for his parents. 
The Empires of the Near East and India 
